OPEN ACCESS

Edited by:

Uday Kishore,

Brunel University London,

United Kingdom

Reviewed by:

Chaofeng Han,

Second Military Medical

University, China

Paramananda Saikia,

Cleveland Clinic, United States

*Correspondence:

Hangping Yao

yaohangping@zju.edu.cn

Qiang Fang

1183005@zju.edu.cn

Specialty section:

This article was submitted to

Molecular Innate Immunity,

a section of the journal

Frontiers in Immunology

Received: 01 July 2020

Accepted: 27 August 2020

Published: 07 October 2020

Citation:

Huang L, Fang X, Shi D, Yao S, Wu W,

Fang $Q$ and Yao H (2020) MSP-RON

Pathway: Potential Regulator of

Inflammation and Innate Immunity.

Front. Immunol. 11:569082

doi: 10.3389/fimmu.2020.569082

\section{MSP-RON Pathway: Potential Regulator of Inflammation and Innate Immunity}

\author{
Lingtong Huang ${ }^{1}$, Xueling Fang ${ }^{1}$, Danrong Shi ${ }^{2}$, Shuhao $\mathrm{Yao}^{3}$, Weifang $\mathrm{Wu}^{1}$, Qiang Fang ${ }^{1 *}$ \\ and Hangping $\mathrm{YaO}^{2 *}$ \\ ${ }^{1}$ Department of Critical Care Units, The First Affiliated Hospital, Zhejiang University School of Medicine, Hangzhou, China, \\ ${ }^{2}$ State Key Laboratory for Diagnosis \& Treatment of Infectious Diseases, National Clinical Research Center for Infectious \\ Diseases, Collaborative Innovation Center for Diagnosis and Treatment of Infectious Diseases, The First Affiliated Hospital, \\ Zhejiang University School of Medicine, Hangzhou, China, ${ }^{3}$ Department of Stormotologry, Wenzhou Medical University Renji \\ College, Wenzhou, China
}

Macrophage-stimulating protein (MSP), a soluble protein mainly synthesized by the liver, is the only known ligand for recepteur d'origine nantais $(R O N)$, which is a member of the MET proto-oncogene family. Recent studies show that the MSP-RON signaling pathway not only was important in tumor behavior but also participates in the occurrence or development of many immune system diseases. Activation of $\mathrm{RON}$ in macrophages results in the inhibition of nitric oxide synthesis as well as lipopolysaccharide (LPS)-induced inflammatory response. MSP-RON is also associated with chronic inflammatory responses, especially chronic liver inflammation, and might serve as a novel regulator of inflammation, which may affect the metabolism in the body. Another study provided evidence of the relationship between MSP-RON and autoimmune diseases, suggesting a potential role for MSP-RON in the development of drugs for autoimmune diseases. Moreover, MSP-RON plays an important role in maintaining the stability of the tissue microenvironment and contributes to immune escape in the tumor immune microenvironment. Here, we summarize the role of MSP-RON in immunity, based on recent findings, and lay the foundation for further research.

Keywords: MSP, RON, macrophage, innate immunity, inflammation, autoimmune disease

\section{HIGHLIGHTS}

- This review focuses mainly on the role of the MSP-RON signaling axis in inflammation and innate immunity.

- The objectives of this study are to summarize the major findings in this research field, to establish the importance of MSP-RON signaling in inflammation and innate immunity, and to provide a foundation for future experiments and studies.

- This review covers four topics: an introduction to MSP and RON, the biological functions of RON in innate immunity, the role of MSP-RON in acute and chronic inflammation, and aberrant RON signaling in autoimmune diseases and its influence on the tissue microenvironment.

- Abnormal activation or inhibition of the MSP-RON signaling axis is a potential strategy for drug development. 
Timeline: The discovery of MSP-RON and it's functions in inflammation and innate immunity.

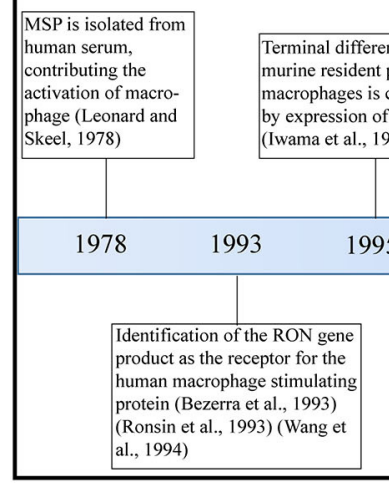

FIGURE 1 | Timeline. In this figure, we illustrate the timeline of MSP-RON discovery and its role in inflammation and innate immunity.

\section{INTRODUCTION}

Macrophage-stimulating protein (MSP) was first purified in 1978 (1) and is secreted by the liver and released into the blood (2) [Figure 1 (Timeline)]. Pro-MSP, with a molecular weight of $78 \mathrm{kDa}$, is cleaved by various enzymatic systems to form a biologically active MSP, consisting of $\alpha$ and $\beta$ chains, and characterized by the presence of a highly conserved Kringle domain (3). The $\beta$ chain of MSP binds to the transmembrane protein RON (recepteur d'origine nantais, also known as MST1R or $\mathrm{CD} 136 \mathrm{w}$ ) but has no biological activity alone; only the complete mature MSP exhibits biological activity (4). MSP is of great interest to researchers due to its function in promoting migration and phagocytosis by activating macrophages $(1,3)$ and regulating the inflammatory response of macrophages (5). RON is a member of the MET family of receptor tyrosine kinases (RTKs) and was isolated from a cDNA library in 1993 (6) and named as stem cell-derived tyrosine kinase (STK) in mice (7, 8). MSP was subsequently shown to be a ligand for the RON receptor (9).

MSP can bind to RON on the surface of tissue-resident macrophages, thereby inhibiting inflammatory response (10). MSP-RON is also associated with autoimmune diseases, such as inflammatory bowel disease (11) and multiple sclerosis (MS) (12). In addition, RON has been shown to be abnormally expressed on many cancer cells, thus promoting tumor migration and proliferation (13-15). Phosphorylation of Tyr1238 and Tyr1239 of RON activates ERK and PI3K/AKT and subsequently mediates tumor proliferation and survival (13). Tyrosine kinase inhibitors and some monoclonal antibodies of RON receptor have been shown to inhibit the growth and proliferation

\footnotetext{
Abbreviations: MSP, macrophage-stimulating protein; RON, recepteur d'origine nantais; STK, stem cell-derived tyrosine kinase; RTK, tyrosine kinase receptor; SHP, small heterodimer partner; TLR, toll-like receptor; SNP, single nucleotide polymorphism; Arg1, arginase 1; IBD, inflammation bowel disease; PSC, primary sclerosing cholangitis; MS, multiple sclerosis.
}

of various tumors such as triple-negative breast cancer and pancreatic ductal adenocarcinoma $(14,15)$.

In recent years, more and more studies show that the MSP-RON signaling pathway plays an important role in immunity and various immune diseases. This article reviews the role of MSP-RON in the immune system, which participates in acute disease, chronic disease, and tumor immune escape, and highlights few key research questions that need to be addressed.

\section{RTKS AND ACTIVATION OF RON}

RTKs play an important role in the body. There are similar intracellular segments in different receptor families, which regulate similar signaling pathways and exhibit similar functions, including activation of the PI3/Akt and Erk1/2 signaling pathways to promote cell proliferation, differentiation, migration, and cell cycle progression (16). The RTKs, TYRO3, AXL (also known as UFO), and MERTK exhibit immune effects similar to those of MSP-RON activation, including promoting M2 differentiation of macrophages, reducing the production of pro-inflammatory factors, and antagonizing the Toll-like receptor downstream pathway (17).

MET, a subfamily of RTKs, consists of two members, MET and RON. Their extracellular SEMA domain is the key to identify with other RTKs (16). MET and RON have similar but not identical SEMA domains, which may account for their structural similarity, but different biological functions (18). Crystal structure analysis confirmed that one MSP molecule interacts with the SEMA domains of two RON molecules to cause receptor dimerization and activation, thereby activating the downstream Akt and Erk1/2 pathways (13). Further, in a study by Angeloni et al., addition of soluble RON-related SEMA proteins or SEMA + PSI proteins during macrophage culture, to competitively bind MSP, weakened the binding of MSP to RON receptors on macrophages and inhibited the activation of downstream pathways, indicating the specific binding of MSP to SEMA domain and suggesting that soluble RON-related SEMA proteins may be used for blocking the MSP-RON pathway (19). 


\section{MSP-RON INVOLVES IN IMMUNE SYSTEM}

MSP can activate RON in tissue-resident macrophages in the liver (20), lung (21), bone (22, 23), and brain (24) as well as tumor-associated macrophages (25) to regulate macrophage phagocytosis (26), migration $(27,28)$, and other functions. MSPRON also promotes epithelial cell proliferation following injury (29), participates in tissue repair (30), and promotes lung ciliary movement $(29,31)$. Therefore, it also plays a role in nonspecific immunity.

RON expression can be used as a marker of terminal differentiation of resident macrophages (32). Cell behavioral changes caused by pathway activation are different in different cells. The most typical behavioral change in macrophages caused by the activation of MSP-RON is the activation of downstream PI3/Akt, which promotes phagocytosis of complement C3bicoated red cells through CR3 and ICAM-1; besides, treatment with the PI3K inhibitors, wortmannin and LY294002, can inhibit this effect (22). MSP, at an optimal dose of $0.2 \mathrm{nM}$, can also induce the migration of resident peritoneal macrophages in a short time (27). MSP-RON-induced activation of osteoclasts, a special type of bone tissue-resident macrophages, enhances osteoclast bone resorption capacity (22) but does not enhance proliferation (33). During breast cancer bone metastasis, because breast cancer cells secrete more MSP, the MSP-RON pathway is activated in the osteoclasts, resulting in bone destruction; however, treatment with the RON inhibitor BMS777607/ASLAN002 can reduce bone destruction and decrease the expression of osteolytic markers in patients with breast cancer (23). While RON is highly expressed in the lung ciliated epithelial cells, MSP is found in high concentration in the bronchial epithelial cells, and activation of MSP-RON increases the ciliary beat frequency (29). The possible reason is the colocalization and physical binding of receptor for hyaluronic acid-mediated motility and RON, and functional changes in RON and ciliary beat frequency occur by decomposing high-molecularweight hyaluronic acid into low-molecular-weight hyaluronic acid fragments and combining with receptor for hyaluronic acid-mediated motility (31), which may contribute to nonspecific immunity.

When infected with Epstein-Barr virus, latent membrane protein 1, an oncoprotein associated with Epstein-Barr virus, can promote the binding of NF- $\mathrm{KB}$ to the RON promoter, inducing the expression of $\mathrm{RON}$ in $\mathrm{B}$ cells and promoting tumor cell proliferation (34). MSP-RON activation is also sufficient to replace erythropoietin for erythroid cell proliferation; induce the phosphorylation of Gab1, MAPK, and PKB; and enhance the proliferation of erythroid progenitor cells (35). However, it seems that the activation of the MSP-RON pathway varies in different cells. In STK/RON-transfected $\mathrm{Ba} / \mathrm{F} 3$ pro-B cells, MSP stimulation promoted proliferation, while in STK/RON-transfected mouse erythroleukemia cells, it resulted in apoptosis (36), which is inconsistent with the previous finding of the antiapoptotic effect of MSP-RON activation through PI3/Akt and Erk1/2 $(37,38)$.

\section{The Regulation of Acute Inflammation}

During acute inflammation, MSP-RON can activate the PI3/Akt pathway, which is necessary to inhibit the expression of nitric oxide synthase in macrophages (10). MSP-RON can also activate the LKB1-AMPK pathway to induce the orphan nuclear receptor small heterodimer partner (SHP) transcription, thereby inhibiting TRAF6 polyubiquitination and suppressing Toll-like receptor (TLR) signaling (39) (Figure 2). In addition, increase in SHP expression inhibits assembly of NLRP3 inflammasome and maturation of interleukin (IL)-1 $\beta$ (40) (Figure 2). Studies have shown that nitric oxide production induced by lipopolysaccharide (LPS) strongly inhibits the mRNA and protein expression of RON in mouse peritoneal macrophages within $72 \mathrm{~h}$, and the combined use of tumor necrosis factor- $\alpha$ and interferon- $\gamma$ also produces similar results; this effect can be antagonized by stimulation with MSP or transforming growth factor- $\beta$ (10). However, some studies have obtained different results. Treatment of mice with $3 \mathrm{mg} / \mathrm{kg}$ LPS was shown to induce RON mRNA and protein expression in liver macrophages and endothelial cells (42). Further, co-stimulation of FVB mice with LPS and MSP increased the expression of RON more significantly than stimulation with LPS alone (43).

Activation of the MSP-RON pathway antagonizes LPSinduced inflammatory factor production $(20,42)$ and reduces LPS-induced peritoneal macrophage apoptosis (55). Moreover, the lack of RON receptors impairs the anti-inflammatory ability of mice after LPS stimulation $(56,57)$, with increased liver $(20)$ and lung tissue damage $(21,58,59)$. A previous study showed that, in a classic mouse model of sepsis, the survival time of RON knockout mice was significantly reduced, and colony formation in systemic organs was significantly increased, accompanied by increased liver damage (44) (Table 1). This may be because RON knockout resulted in reduced production of IL- 6 , macrophage inflammatory protein-2, and monocyte chemotactic protein-1, which are important for neutrophil mobilization by macrophages (44). MSP-RON activation in macrophages can inhibit IL12 p40 expression, which may lead to activation of NK cells and $\gamma \delta \mathrm{T}$ cells $(60,61)$. Previously, RON knockout mice were shown to display significantly increased interferon- $\gamma$ production after LPS stimulation (41). RON activation can inhibit the expression of CIITA through the activation of Erk1/2, thus reducing the expression of MHC II in macrophages as well as the ability to activate T cells (41) (Figure 2). This indicates that the MSP-RON pathway not only acts on macrophages but also exerts a wide range of anti-inflammatory effects through signal transmission between cells. In a nickel-induced lung injury model, RON knockout were shown to exhibit enhanced inflammatory response and a significantly shorter survival time (45), suggesting that MSP-RON not only has an antagonistic effect on LPS-induced production of inflammatory mediators but also has protective effects on inflammatory responses induced by other substances. Interestingly, in FVB mice with M2 susceptibility, the TLR4 pathway is more significantly antagonized than that in M1-prone C57/B6 mice (43), thus adding complexity to the understanding of the role of MSPRON in experimental animals and populations of different 


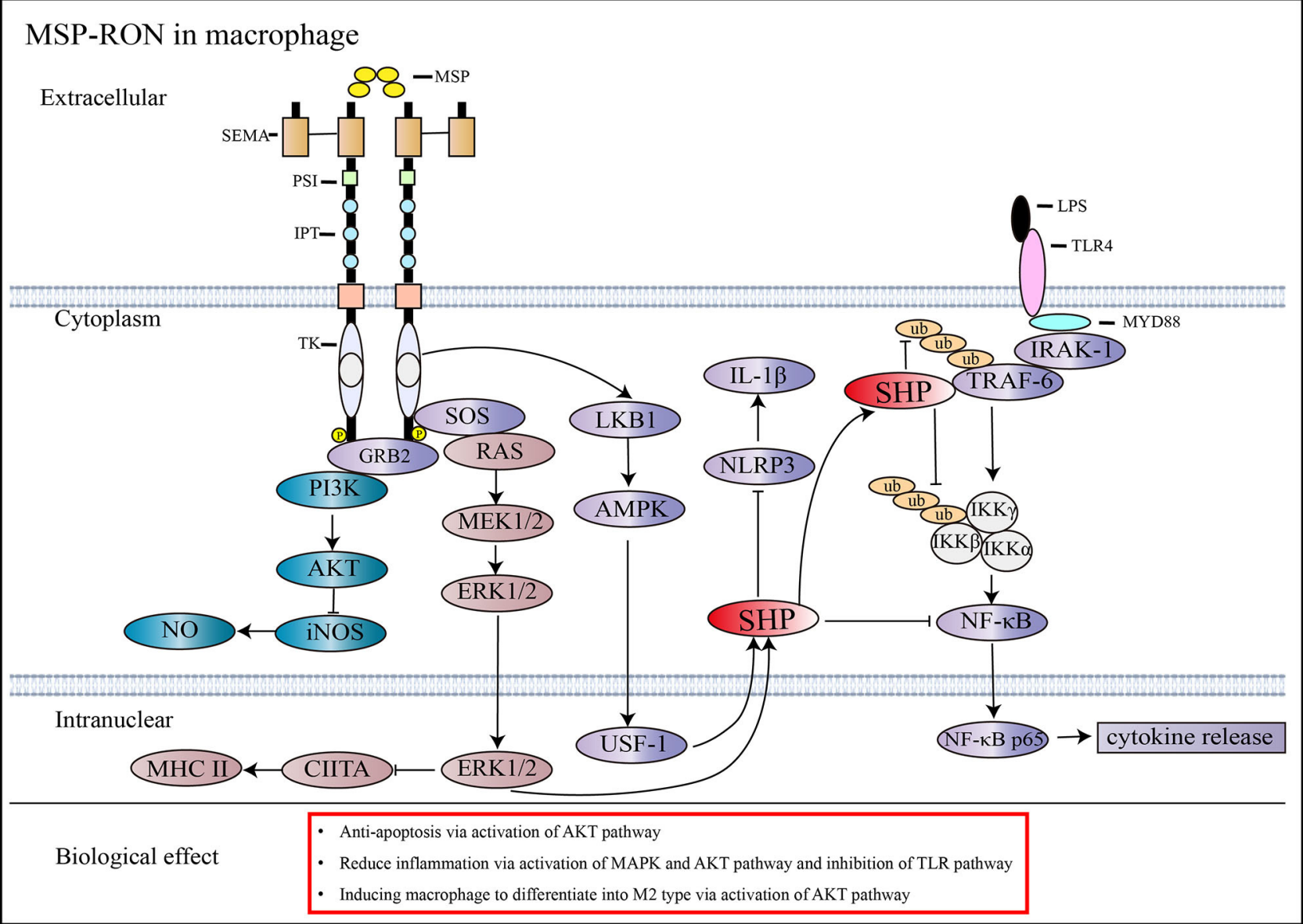

FIGURE 2 | Signaling pathways activated by MSP and RON. MSP induces RON dimerization and activates downstream pathways (13). In macrophages, the activation of RON inhibits iNOS through the AKT pathway and reduces NO synthesis (10). RON activation stimulates SHP expression through the MAPK and AMPK pathways, which can antagonize the TLR4 pathway by inhibiting TRAF6 ubiquitination and preventing NF- $\mathrm{kB}$ from entering the nucleus, thus reducing cytokine production (39). Besides, increased expression of SHP through activation of the MSP-RON pathway can inhibit NLRP3 inflammasome activation, thereby inhibiting cleavage of pro-IL-1 $\beta$ into activated IL-1 $\beta$ (40). MSP-RON activation also inhibits CIITA transcription and, thus, MHC II expression via the MAPK pathway (41).

genetic backgrounds. The activation of MSP-RON in human lung macrophages, especially in the alveolar macrophages of smokers, shows dual anti- and pro-inflammatory effects (62). However, further research is required to clarify the role of MSP-RON in human tissue-resident macrophages.

\section{The Regulation of Chronic Inflammation}

MSP-RON also plays an important role in chronic inflammation. Non-alcoholic steatohepatitis is a liver inflammatory disease caused by continuous stimulation with low-density lipoproteins and LPS (63). In an in vitro model, MSP-RON was shown to antagonize inflammatory response in mouse liver primary cells and bone marrow-derived macrophages induced by oxidized low-density lipoproteins and LPS via activating the AMPK signaling pathway (46). Moreover, activation of RON has been shown to improve diet-induced fibrosis in nonalcoholic fatty liver mice, and RON knockout mice exhibit higher levels of inflammatory cell infiltration, collagen, ECM remodeling proteins, and profibrotic cytokine expression (47).
However, a recent study showed opposite results. In nonalcoholic steatohepatitis mice treated with $500 \mathrm{ng} /$ day of MSP by micropump infusion, liver inflammation was enhanced with increased expression of tumor necrosis factor- $\alpha$, IL-1 $\beta$, CCL2, etc. (64). This study did not report the MSP dose that penetrates into the liver, which may affect the conclusions of the experiment. Similarly, MSP-RON also plays an important role in obesityinduced chronic inflammation. In a mouse obesity model, MSPRON was shown to reduce inflammation, increase tissue repair capacity, and induce macrophages to switch to an M2 phenotype, characterized by increased arginase 1 (Agr1) expression (48). This is in accordance with the results of other studies, which showed that activation of MSP-RON promotes differentiation of macrophages into the M2 phenotype associated with tissue repair, while at the same time weakening macrophage differentiation toward the pro-inflammatory M1 phenotype $(65,66)$.

A similar study by Stuart et al. showed that RON knockout resulted in increased serum levels of inflammatory factors in mice on a high-fat diet; however, this study also showed 
TABLE 1 | MSP-RON with clinical diseases.

\begin{tabular}{|c|c|}
\hline $\begin{array}{l}\text { Classification and } \\
\text { diseases }\end{array}$ & Details \\
\hline \multicolumn{2}{|l|}{ Acute inflammation } \\
\hline Sepsis & The survival time of RON knockout mice reduced with increased liver damage in a sepsis mouse model (44) \\
\hline Acute lung injury & $\begin{array}{l}\text { RON knockout was shown to exhibit enhanced inflammatory response and a significantly shorter survival time through } \\
\text { macrophage in nickel-induced lung injury model (45) }\end{array}$ \\
\hline \multicolumn{2}{|c|}{ Chronic inflammation } \\
\hline $\begin{array}{l}\text { Non-alcoholic } \\
\text { steatohepatitis }\end{array}$ & $\begin{array}{l}\text { MSP-RON antagonizes inflammatory response induced by oxidized low-density lipoproteins and LPS via activating the AMPK } \\
\text { signaling pathway (46). Activation of RON improves diet-induced fibrosis in non-alcoholic fatty liver mice, and RON knockout } \\
\text { mice exhibit higher levels of inflammatory cell infiltration, collagen, ECM remodeling proteins, and profibrotic cytokine } \\
\text { expression (47) }\end{array}$ \\
\hline Obesity & $\begin{array}{l}\text { MSP-RON reduces inflammation, increases tissue repair capacity, and induces macrophages to switch to M2 phenotype in } \\
\text { mouse obesity model (48); RON knockout resulted in increased serum levels of inflammatory factors in mice with high-fat diet (49) }\end{array}$ \\
\hline \multicolumn{2}{|c|}{ Autoimmune diseases } \\
\hline Ulcerative colitis & The expression of RON in intestinal mucosal epithelial cells is higher than that in healthy patients $(50,51)$ \\
\hline Crohn's disease & Genome-wide association studies shows that SNP of rs3197999 in the MSP gene is associated with Crohn's disease (11) \\
\hline $\begin{array}{l}\text { Primary sclerosing } \\
\text { cholangitis }\end{array}$ & Genomics study of PSC patients showed that PSC is related to SNP rs3197999 (MSPRR689C) (52) \\
\hline Multiple sclerosis & $\begin{array}{l}\text { The expression and synthesis of RON were significantly reduced in patients with MS and after RON knockout, central nervous } \\
\text { system inflammation significantly increased in experimental autoimmune encephalomyelitis animal models (12), but SNP } \\
\text { rs3197999 (MSPRR689C) is not associated with MS (53) }\end{array}$ \\
\hline Anti-Thy-1 nephritis & $\begin{array}{l}\text { Promoting mesangial cell proliferation and blood mononuclear cell infiltration, besides antagonizing MSP, could significantly } \\
\text { improve glomerular damage and mesangial proliferation (54). }\end{array}$ \\
\hline
\end{tabular}

that activation of RON leads to increased fat synthesis in the white adipose tissue, which increases the production of pro-inflammatory factors (49). This indicates that the MSPRON pathway is involved in adipogenesis. At present, several studies are focused on the role of MSP-RON in chronic inflammation, especially chronic inflammation related to energy metabolism. As described above, the MSP-RON-AMPK-SHP axis is important in suppressing inflammation caused by TLR activation (39, 40), and SHP can significantly inhibit liver gluconeogenesis (67), which may link MSP-RON with acute inflammation, chronic inflammation, and energy metabolism. Similarly, phosphorylation of RON has been shown to activate the PI3K-Akt-mTOR pathway in tumor cells (13), which further links MSP-RON to energy metabolism and inflammation since mTOR is a key regulator of energy metabolism and mediates immune suppression (68).

\section{Association of MSP-RON With Autoimmune Diseases}

MSP-RON also plays an important role in autoimmune diseases. RON receptors are widely distributed in the gastrointestinal tract, and in patients with ulcerative colitis, the expression of RON in intestinal mucosal epithelial cells is higher than that in healthy patients $(50,51)$. Genome-wide association studies have shown that single nucleotide polymorphism (SNP) of rs3197999 in the MSP gene is closely associated with Crohn's disease (11). A previous research showed that the mismatch of SNP rs3197999 in the MSP gene (MSP $\beta$ R689C) decreased the binding capacity of MSP $\beta$ to RON by 10 fold, which seriously affects the MSP-RON pathway, resulting in the occurrence of inflammatory bowel disease (IBD) (69). However, another study showed that the mismatch of R689C in the MSP protein does not affect its ability to bind to the SEMA domain of RON, but the serum level of MSP is regulated by SNP rs3197999 (MSP $\beta$ R689C), which causes a decrease in serum MSP concentration, and this may be one of the mechanisms of IBD (70). Patients with primary sclerosing cholangitis (PSC) often have IBD, and a large sample genomics study of PSC showed that it is most closely related to SNP rs3197999 (MSPRR689C) (52). Through genomics and proteomics, researchers have linked the MSP-RON pathway with autoimmune diseases, such as IBD and PSC, but more research is needed to explore its pathogenesis and develop strategies for the treatment of IBD and PSC. The MSP-RON pathway has also been shown to be associated with MS. The expression and synthesis of RON were significantly reduced in patients with MS, in animal models of MS, and after RON knockout, and central nervous system inflammation in experimental autoimmune encephalomyelitis animal models significantly increased with nerve demyelination and axonal injury (12). Meanwhile, the expression of c-Cbl, a negative regulator of $\mathrm{RON}$ (71), increases during the onset of MS (12). However, subsequent studies have shown that SNP rs3197999 (MSP $\beta$ R689C) is not associated with MS (53). Hence, more research is needed to elucidate the role of MSP-RON in the pathogenesis and prognosis of MS. Previous studies have also demonstrated a pathogenic role of the MSP-RON 
pathway in anti-Thy- 1 nephritis, including promoting mesangial cell proliferation and blood mononuclear cell infiltration and antagonizing MSP, which can significantly improve glomerular damage and mesangial proliferation (54). Similarly, in a sickle cell disease model, elevated levels of protease membrane type serine protease 1, which can cleave MSP precursors, were reported in monocytes exposed to hemolysis and hypoxia, resulting in abnormal activation of the MSP-RON pathway in renal endothelial cells. This led to renal injury, increasing glomerular permeability. However, treatment with the RONspecific inhibitor BMS777607 significantly reduced glomerular endothelial damage and non-M1 macrophage infiltration in sickle cell disease mice (72).

The role of RON in autoimmune diseases is still not wellstudied. Abnormal activation of MSP-RON signaling leads to the occurrence of autoimmune diseases. However, more research is needed to explore the exact role of the MSP-RON pathway in autoimmune diseases.

\section{Association Between Tissue Microenvironment and MSP-RON}

MSP-RON pathway plays an important role in tissue microenvironment, especially in tumor immune microenvironment. A study by Eyob et al. showed that the loss of RON receptors in mice significantly inhibits breast cancer metastasis by enhancing their anti-tumor capacity and increasing the number of $\mathrm{CD}^{+} \mathrm{T}$ cells (61). RON activation upregulates Fos by activating MAPK, which binds to the Arg1 promoter AP-1 to induce the expression of Arg1, while Arg1 expression in tumor-associated macrophages is significantly reduced in RON knockout mice (25). Moreover, a previous study demonstrated a high number of $\mathrm{CD}^{+} \mathrm{T}$ cells and M1 macrophages and lesser numbers of M2 macrophages in the tumor microenvironment of MSP-deficient mice, which exhibit high tumor killing ability (73). Notably, in a recent study, the activation of MSP-RON in tumorassociated macrophages significantly increased the expression of CD80 and PD-L1, and the combination of anti-RON and anti-CTLA therapy significantly inhibited tumor growth in mice (74). Taken together, previous findings suggest that activation of MSP-RON plays an immunosuppressive role in the tumor

\section{REFERENCES}

1. Leonard EJ, Skeel AH. Isolation of macrophage stimulating protein (MSP) from human serum. Exp Cell Res. (1978) 114:117-26. doi: 10.1016/0014-4827(78)90043-5

2. Bezerra JA, Witte DP, Aronow BJ, Degen SJ. Hepatocyte-specific expression of the mouse hepatocyte growth factor-like protein. Hepatology. (1993) 18:394-9. doi: 10.1016/0270-9139(93)90024-H

3. Skeel A, Yoshimura T, Showalter SD, Tanaka S, Appella E, Leonard EJ. Macrophage stimulating protein: purification, partial amino acid sequence, and cellular activity. J Exp Med. (1991) 173:1227-34. doi: 10.1084/jem.173.5.1227

4. Wang MH, Julian FM, Breathnach R, Godowski PJ, Takehara T, Yoshikawa W, et al. Macrophage stimulating protein (MSP) binds to its receptor via the MSP beta chain. J Biol Chem. (1997) 272:16999-7004. doi: 10.1074/jbc.272.27.16999 microenvironment, and inhibition of MSP-RON activation may serve as a potential strategy for anti-tumor therapy.

\section{CONCLUSION}

The MSP-RON pathway mediates inflammatory response in the body. Abnormalities in the MSP-RON pathway lead to the occurrence of autoimmune diseases, and excessive activation of MSP-RON promotes tumor progression. However, we rarely see the use of clinical samples to detect the role of the MSP-RON signaling pathway in the immune system and certain questions need to be addressed. The extent of MSP-RON activation in immunity and its impact on the disease, as well as the clinical potential of MSP-RON signaling need to be further evaluated. In addition, the molecular mechanisms underlying MSP-RON signaling in autoimmune diseases need to be clarified. Further, verification of the effectiveness of therapeutic drugs in disease treatment is also necessary. Clarification of these questions will contribute to evaluate the exact role of MSP-RON in innate immunity and evaluate its potential for clinical application.

\section{AUTHOR CONTRIBUTIONS}

LH and XF performed the literature search, drafted the manuscript, and prepared the figures. LH, XF, DS, SY, and WW helped perform revisions and critically discussed the manuscript. QF and HY designed, supervised, and critically reviewed the final manuscript. All authors contributed to the article and approved the submitted version.

\section{FUNDING}

This work was supported by the National Natural Science Foundation of China (Grant No. \#81872883 to HY), the National Science \& Technology Major Project of China (Grant No. \#2017ZX10204401 to QF), and the Medical Health Science and Technology Project of Zhejiang Province Health Commission (Grant No. \#2018KY379 to WW). The funders had no role in the decision to publish or preparation of the manuscript.
5. Wang MH, Zhou YQ, Chen YQ. Macrophage-stimulating protein and RON receptor tyrosine kinase: potential regulators of macrophage inflammatory activities. Scand J Immunol. (2002) 56:545-53. doi: 10.1046/j.1365-3083.2002.01177.x

6. Ronsin C, Muscatelli F, Mattei MG, Breathnach R. A novel putative receptor protein tyrosine kinase of the met family. Oncogene. (1993) 8:1195-202.

7. Iwama A, Okano K, Sudo T, Matsuda Y, Suda T. Molecular cloning of a novel receptor tyrosine kinase gene, STK, derived from enriched hematopoietic stem cells. Blood. (1994) 83:3160-9. doi: 10.1182/blood.V83.11.3160.3160

8. Wang $M H$, Iwama A, Skeel A, Suda T, Leonard EJ. The murine stk gene product, a transmembrane protein tyrosine kinase, is a receptor for macrophage-stimulating protein. Proc Natl Acad Sci USA. (1995) 92:3933-7. doi: 10.1073/pnas.92.9.3933

9. Wang MH, Ronsin C, Gesnel MC, Coupey L, Skeel A, Leonard EJ, et al. Identification of the ron gene product as the receptor for 
the human macrophage stimulating protein. Science. (1994) 266:117-9. doi: 10.1126/science.7939629

10. Chen YQ, Fisher JH, Wang MH. Activation of the RON receptor tyrosine kinase inhibits inducible nitric oxide synthase (iNOS) expression by murine peritoneal exudate macrophages: phosphatidylinositol-3 kinase is required for RON-mediated inhibition of iNOS expression. J Immunol. (1998) 161:4950-9.

11. Franke A, Mcgovern DP, Barrett JC, Wang K, Radford-Smith GL, Ahmad $\mathrm{T}$, et al. Genome-wide meta-analysis increases to 71 the number of confirmed Crohn's disease susceptibility loci. Nat Genet. (2010) 42:1118-25. doi: $10.1038 /$ ng. 717

12. Tsutsui S, Noorbakhsh F, Sullivan A, Henderson AJ, Warren K, Toney-Earley $\mathrm{K}$, et al. RON-regulated innate immunity is protective in an animal model of multiple sclerosis. Ann Neurol. (2005) 57:883-95. doi: 10.1002/ana.20502

13. Yao HP, Zhou YQ, Zhang R, Wang MH. MSP-RON signalling in cancer: pathogenesis and therapeutic potential. Nat Rev Cancer. (2013) 13:466-81. doi: $10.1038 / \operatorname{nrc} 3545$

14. Yao HP, Hudson R, Wang MH. RON receptor tyrosine kinase in pancreatic ductal adenocarcinoma: pathogenic mechanism in malignancy and pharmaceutical target for therapy. Biochim Biophys Acta Rev Cancer. (2020) 1873:188360. doi: 10.1016/j.bbcan.2020.188360

15. Yao HP, Suthe SR, Hudson R, Wang MH. Antibody-drug conjugates targeting RON receptor tyrosine kinase as a novel strategy for treatment of triple-negative breast cancer. Drug Discov Today. (2020) 25:1160-73. doi: 10.1016/j.drudis.2020.05.012

16. Lemmon MA, Schlessinger J. Cell signaling by receptor tyrosine kinases. Cell. (2010) 141:1117-34. doi: 10.1016/j.cell.2010.06.011

17. Graham DK, Deryckere D, Davies KD, Earp HS. The TAM family: phosphatidylserine sensing receptor tyrosine kinases gone awry in cancer. Nat Rev Cancer. (2014) 14:769-85. doi: 10.1038/nrc3847

18. Gherardi E, Love CA, Esnouf RM, Jones EY. The sema domain. Curr Opin Struct Biol. (2004) 14:669-78. doi: 10.1016/j.sbi.2004.10.010

19. Angeloni D, Danilkovitch-Miagkova A, Miagkov A, Leonard EJ, Lerman MI. The soluble sema domain of the RON receptor inhibits macrophagestimulating protein-induced receptor activation. J Biol Chem. (2004) 279:3726-32. doi: 10.1074/jbc.M309342200

20. Stuart WD, Kulkarni RM, Gray JK, Vasiliauskas J, Leonis MA, Waltz SE. Ron receptor regulates kupffer cell-dependent cytokine production and hepatocyte survival following endotoxin exposure in mice. Hepatology. (2011) 53:161828. doi: 10.1002/hep. 24239

21. Nikolaidis NM, Gray JK, Gurusamy D, Fox W, Stuart WD, Huber N, et al. Ron receptor tyrosine kinase negatively regulates TNFalpha production in alveolar macrophages by inhibiting NF-kappaB activity and Adam17 production. Shock. (2010) 33:197-204. doi: 10.1097/SHK.0b013e3181ae8155

22. Kurihara N, Iwama A, Tatsumi J, Ikeda K, Suda T. Macrophagestimulating protein activates STK receptor tyrosine kinase on osteoclasts and facilitates bone resorption by osteoclast-like cells. Blood. (1996) 87:3704-10. doi: 10.1182/blood.V87.9.3704.bloodjournal8793704

23. Andrade K, Fornetti J, Zhao L, Miller SC, Randall RL, Anderson N, et al. RON kinase: a target for treatment of cancer-induced bone destruction and osteoporosis. Sci Transl Med. (2017) 9:eaai9338. doi: 10.1126/scitranslmed.aai9338

24. Dey A, Allen JN, Fraser JW, Snyder LM, Tian Y, Zhang L, et al. Neuroprotective role of the ron receptor tyrosine kinase underlying central nervous system inflammation in health and disease. Front Immunol. (2018) 9:513. doi: 10.3389/fimmu.2018.00513

25. Sharda DR, Yu S, Ray M, Squadrito ML, De Palma M, Wynn TA, et al. Regulation of macrophage arginase expression and tumor growth by the ron receptor tyrosine kinase. J Immunol. (2011) 187:2181-92. doi: 10.4049/jimmunol.1003460

26. Lutz MA, Correll PH. Activation of CR3-mediated phagocytosis by MSP requires the RON receptor, tyrosine kinase activity, phosphatidylinositol 3-kinase, and protein kinase C zeta. J Leukoc Biol. (2003) 73:802-14. doi: $10.1189 / \mathrm{jlb} .0602319$

27. Skeel A, Leonard EJ. Action and target cell specificity of human macrophagestimulating protein (MSP). J Immunol. (1994) 152:4618-23.

28. Wang MH, Dlugosz AA, Sun Y, Suda T, Skeel A, Leonard EJ. Macrophagestimulating protein induces proliferation and migration of murine keratinocytes. Exp Cell Res. (1996) 226:39-46. doi: 10.1006/excr.1996.0200
29. Sakamoto O, Iwama A, Amitani R, Takehara T, Yamaguchi N, Yamamoto $\mathrm{T}$, et al. Role of macrophage-stimulating protein and its receptor, RON tyrosine kinase, in ciliary motility. J Clin Invest. (1997) 99:701-9. doi: 10.1172/JCI119214

30. Nanney LB, Skeel A, Luan J, Polis S, Richmond A, Wang MH, et al. Proteolytic cleavage and activation of pro-macrophage-stimulating protein and upregulation of its receptor in tissue injury. J Invest Dermatol. (1998) 111:573-81. doi: 10.1046/j.1523-1747.1998.00332.x

31. Manzanares D, Monzon ME, Savani RC, Salathe M. Apical oxidative hyaluronan degradation stimulates airway ciliary beating via RHAMM and RON. Am J Respir Cell Mol Biol. (2007) 37:160-8. doi: $10.1165 / \mathrm{rcmb} .2006-0413 \mathrm{OC}$

32. Iwama $\mathrm{A}$, Wang $\mathrm{MH}$, Yamaguchi $\mathrm{N}$, Ohno $\mathrm{N}$, Okano $\mathrm{K}$, Sudo $\mathrm{T}$, et al. Terminal differentiation of murine resident peritoneal macrophages is characterized by expression of the STK protein tyrosine kinase, a receptor for macrophage-stimulating protein. Blood. (1995) 86:3394-403. doi: 10.1182/blood.V86.9.3394.bloodjournal8693394

33. Kurihara N, Tatsumi J, Arai F, Iwama A, Suda T. Macrophage-stimulating protein (MSP) and its receptor, RON, stimulate human osteoclast activity but not proliferation: effect of MSP distinct from that of hepatocyte growth factor. Exp Hematol. (1998) 26:1080.

34. Chou YC, Lin SJ, Lu J, Yeh TH, Chen CL, Weng PL, et al. Requirement for LMP1-induced RON receptor tyrosine kinase in epstein-barr virus-mediated B-cell proliferation. Blood. (2011) 118:1340-9. doi: 10.1182/blood-2011-02-335448

35. Van Den Akker E, Van Dijk T, Parren-Van Amelsvoort M, Grossmann KS, Schaeper U, Toney-Earley K, et al. Tyrosine kinase receptor RON functions downstream of the erythropoietin receptor to induce expansion of erythroid progenitors. Blood. (2004) 103:4457-65. doi: 10.1182/blood-2003-08-2713

36. Iwama A, Yamaguchi N, Suda T. STK/RON receptor tyrosine kinase mediates both apoptotic and growth signals via the multifunctional docking site conserved among the HGF receptor family. EMBO J. (1996) 15:5866-75. doi: 10.1002/j.1460-2075.1996.tb00973.x

37. Lee KE, Kim EY, Kim CS, Choi JS, Bae EH, Ma SK, et al. Macrophagestimulating protein attenuates gentamicin-induced inflammation and apoptosis in human renal proximal tubular epithelial cells. Biochem Biophys Res Commun. (2013) 434:527-33. doi: 10.1016/j.bbrc.2013.03.108

38. Lee KE, Kim EY, Kim CS, Choi JS, Bae EH, Ma SK, et al. Macrophagestimulating protein attenuates hydrogen peroxide-induced apoptosis in human renal HK-2 cells. Eur J Pharmacol. (2013) 715:304-11. doi: 10.1016/j.ejphar.2013.05.006

39. Yuk JM, Shin DM, Lee HM, Kim JJ, Kim SW, Jin HS, et al. The orphan nuclear receptor SHP acts as a negative regulator in inflammatory signaling triggered by Toll-like receptors. Nat Immunol. (2011) 12:742-51. doi: 10.1038/ni.2064

40. Yang CS, Kim JJ, Kim TS, Lee PY, Kim SY, Lee HM, et al. Small heterodimer partner interacts with NLRP3 and negatively regulates activation of the NLRP3 inflammasome. Nat Commun. (2015) 6:6115. doi: 10.1038/ncomms7115

41. Wilson CB, Ray M, Lutz M, Sharda D, Xu J, Hankey PA. The RON receptor tyrosine kinase regulates IFN-gamma production and responses in innate immunity. J Immunol. (2008) 181:2303-10. doi: 10.4049/jimmunol.181.4.2303

42. Laskin DL, Chen L, Hankey PA, Laskin JD. Role of STK in mouse liver macrophage and endothelial cell responsiveness during acute endotoxemia. J Leukoc Biol. (2010) 88:373-82. doi: 10.1189/jlb.0210113

43. Chaudhuri A, Wilson NS, Yang B, Paler Martinez A, Liu J, Zhu C, et al. Host genetic background impacts modulation of the TLR4 pathway by RON in tissue-associated macrophages. Immunol Cell Biol. (2013) 91:451-60. doi: $10.1038 /$ icb.2013.27

44. Caldwell CC, Martignoni A, Leonis MA, Ondiveeran HK, Fox-Robichaud AE, Waltz SE. Ron receptor tyrosine kinase-dependent hepatic neutrophil recruitment and survival benefit in a murine model of bacterial peritonitis. Crit Care Med. (2008) 36:1585-93. doi: 10.1097/CCM.0b013e318170a8c2

45. Mcdowell SA, Mallakin A, Bachurski CJ, Toney-Earley K, Prows DR, Bruno $\mathrm{T}$, et al. The role of the receptor tyrosine kinase Ron in nickelinduced acute lung injury. Am J Respir Cell Mol Biol. (2002) 26:99-104. doi: $10.1165 /$ ajrcmb.26.1.4621

46. Chanda D, Li J, Oligschlaeger Y, Jeurissen ML, Houben T, Walenbergh SM, et al. MSP is a negative regulator of inflammation and lipogenesis in ex 
vivo models of non-alcoholic steatohepatitis. Exp Mol Med. (2016) 48:e258. doi: 10.1038/emm.2016.79

47. Allen J, Zhang J, Quickel MD, Kennett M, Patterson AD, Hankey-Giblin PA. Ron receptor signaling ameliorates hepatic fibrosis in a diet-induced nonalcoholic steatohepatitis mouse model. J Proteome Res. (2018) 17:3268-80. doi: 10.1021/acs.jproteome.8b00379

48. Yu S, Allen JN, Dey A, Zhang L, Balandaram G, Kennett MJ, et al. The ron receptor tyrosine kinase regulates macrophage heterogeneity and plays a protective role in diet-induced obesity, atherosclerosis, and hepatosteatosis. J Immunol. (2016) 197:256-65. doi: 10.4049/jimmunol.1600450

49. Stuart WD, Brown NE, Paluch AM, Waltz SE. Loss of Ron receptor signaling leads to reduced obesity, diabetic phenotypes and hepatic steatosis in response to high-fat diet in mice. Am J Physiol Endocrinol Metab. (2015) 308:E562-72. doi: 10.1152/ajpendo.00467.2014

50. Hirayama I, Ide M, Asao T, Kuwano H. Receptor protein tyrosine kinase ron is highly expressed in colorectal mucosa of ulcerative colitis patients. Hepatogastroenterology. (2007) 54:1672-5.

51. Kauder SE, Santell L, Mai E, Wright LY, Luis E, N'diaye EN, et al. Functional consequences of the macrophage stimulating protein $689 \mathrm{C}$ inflammatory bowel disease risk allele. PLoS ONE. (2013) 8:e83958. doi: 10.1371/journal.pone. 0083958

52. Melum E, Franke A, Schramm C, Weismuller TJ, Gotthardt DN, Offner FA, et al. Genome-wide association analysis in primary sclerosing cholangitis identifies two non-HLA susceptibility loci. Nat Genet. (2011) 43:17-9. doi: $10.1038 /$ ng. 728

53. Marquez A, Cenit MC, Nunez C, Mendoza JL, Taxonera C, Diaz-Rubio $\mathrm{M}$, et al. Effect of BSN-MST1 locus on inflammatory bowel disease and multiple sclerosis susceptibility. Genes Immun. (2009) 10:631-5. doi: 10.1038/gene.2009.56

54. Rampino T, Soccio G, Gregorini M, Guidetti C, Marasa M, Maggio M, et al. Neutralization of macrophage-stimulating protein ameliorates renal injury in anti-thy 1 glomerulonephritis. J Am Soc Nephrol. (2007) 18:1486-96. doi: 10.1681/ASN.2006060680

55. Chen YQ, Zhou YQ, Wang MH. Activation of the RON receptor tyrosine kinase protects murine macrophages from apoptotic death induced by bacterial lipopolysaccharide. J Leukoc Biol. (2002) 71:359-66.

56. Muraoka RS, Sun WY, Colbert MC, Waltz SE, Witte DP, Degen JL, et al. The Ron/STK receptor tyrosine kinase is essential for periimplantation development in the mouse. J Clin Invest. (1999) 103:1277-85. doi: 10.1172/JCI6091

57. Waltz SE, Eaton L, Toney-Earley K, Hess KA, Peace BE, Ihlendorf JR, et al. Ron-mediated cytoplasmic signaling is dispensable for viability but is required to limit inflammatory responses. J Clin Invest. (2001) 108:567-76. doi: 10.1172/JCI11881

58. Lentsch AB, Pathrose $P$, Kader S, Kuboki S, Collins MH, Waltz SE. The Ron receptor tyrosine kinase regulates acute lung injury and suppresses nuclear factor kappaB activation. Shock. (2007) 27:274-80. doi: 10.1097/01.shk.0000239755.82711.89

59. Nikolaidis NM, Kulkarni RM, Gray JK, Collins MH, Waltz SE. Ron receptor deficient alveolar myeloid cells exacerbate LPS-induced acute lung injury in the murine lung. Innate Immun. (2011) 17:499-507. doi: $10.1177 / 1753425910383725$

60. Morrison AC, Wilson CB, Ray M, Correll PH. Macrophage-stimulating protein, the ligand for the stem cell-derived tyrosine kinase/RON receptor tyrosine kinase, inhibits IL-12 production by primary peritoneal macrophages stimulated with IFN-gamma and lipopolysaccharide. J Immunol. (2004) 172:1825-32. doi: 10.4049/jimmunol.172.3.1825

61. Eyob H, Ekiz HA, Derose YS, Waltz SE, Williams MA, Welm AL. Inhibition of ron kinase blocks conversion of micrometastases to overt metastases by boosting antitumor immunity. Cancer Discov. (2013) 3:751-60. doi: 10.1158/2159-8290.CD-12-0480
62. Gunella G, Bardelli C, Amoruso A, Viano I, Balbo P, Brunelleschi S. Macrophage-stimulating protein differently affects human alveolar macrophages from smoker and non-smoker patients: evaluation of respiratory burst, cytokine release and NF-kappaB pathway. Br J Pharmacol. (2006) 148:478-89. doi: 10.1038/sj.bjp.0706751

63. Walenbergh SM, Koek GH, Bieghs V, Shiri-Sverdlov R. Non-alcoholic steatohepatitis: the role of oxidized low-density lipoproteins. J Hepatol. (2013) 58:801-10. doi: 10.1016/j.jhep.2012.11.014

64. Li J, Chanda D, Van Gorp PJ, Jeurissen ML, Houben T, Walenbergh SM, et al. Macrophage stimulating protein enhances hepatic inflammation in a NASH model. PLoS ONE. (2016) 11:e0163843. doi: 10.1371/journal.pone.0163843

65. Morrison AC, Correll PH. Activation of the stem cell-derived tyrosine kinase/RON receptor tyrosine kinase by macrophage-stimulating protein results in the induction of arginase activity in murine peritoneal macrophages. J Immunol. (2002) 168:853-60. doi: 10.4049/jimmunol. 168.2.853

66. Chaudhuri A. Regulation of macrophage polarization by RON receptor tyrosine kinase signaling. Front Immunol. (2014) 5:546. doi: 10.3389/fimmu.2014.00546

67. Chanda D, Li T, Song KH, Kim YH, Sim J, Lee CH, et al. Hepatocyte growth factor family negatively regulates hepatic gluconeogenesis via induction of orphan nuclear receptor small heterodimer partner in primary hepatocytes. J Biol Chem. (2009) 284:28510-21. doi: 10.1074/jbc.M109. 022244

68. Saxton RA, Sabatini DM. mTOR signaling in growth, metabolism, and disease. Cell. (2017) 168:960-76. doi: 10.1016/j.cell.2017.02.004

69. Gorlatova N, Chao K, Pal LR, Araj RH, Galkin A, Turko I, et al. Protein characterization of a candidate mechanism SNP for Crohn's disease: the macrophage stimulating protein R689C substitution. PLoS ONE. (2011) 6:e27269. doi: 10.1371/journal.pone.0027269

70. Di Narzo AF, Telesco SE, Brodmerkel C, Argmann C, Peters LA, Li K, et al. High-throughput characterization of blood serum proteomics of IBD patients with respect to aging and genetic factors. PLoS Genet. (2017) 13:e1006565. doi: 10.1371/journal.pgen.1006565

71. Penengo L, Rubin C, Yarden Y, Gaudino G. c-Cbl is a critical modulator of the ron tyrosine kinase receptor. Oncogene. (2003) 22:3669-79. doi: 10.1038/sj.onc. 1206585

72. Khaibullina A, Adjei EA, Afangbedji N, Ivanov A, Kumari N, Almeida LEF, et al. RON kinase inhibition reduces renal endothelial injury in sickle cell disease mice. Haematologica. (2018) 103:787-98. doi: 10.3324/haematol.2017.180992

73. Benight NM, Wagh PK, Zinser GM, Peace BE, Stuart WD, Vasiliauskas J, et al. HGFL supports mammary tumorigenesis by enhancing tumor cell intrinsic survival and influencing macrophage and T-cell responses. Oncotarget. (2015) 6:17445-61. doi: 10.18632/oncotarget.3641

74. Ekiz HA, Lai SA, Gundlapalli H, Haroun F, Williams MA, Welm AL. Inhibition of RON kinase potentiates anti-CTLA-4 immunotherapy to shrink breast tumors and prevent metastatic outgrowth. Oncoimmunology. (2018) 7:e1480286. doi: 10.1080/2162402X.2018.1480286

Conflict of Interest: The authors declare that the research was conducted in the absence of any commercial or financial relationships that could be construed as a potential conflict of interest.

Copyright (๑) 2020 Huang, Fang, Shi, Yao, Wu, Fang and Yao. This is an open-access article distributed under the terms of the Creative Commons Attribution License (CC $B Y)$. The use, distribution or reproduction in other forums is permitted, provided the original author(s) and the copyright owner(s) are credited and that the original publication in this journal is cited, in accordance with accepted academic practice. No use, distribution or reproduction is permitted which does not comply with these terms. 